\title{
Uncertainty modeling and visualization for tsunami hazard and risk mapping: a case study for the 2011 Tohoku earthquake
}

\author{
Katsuichiro Goda ${ }^{1} \cdot$ Jie Song $^{1}$
}

Published online: 30 August 2015

(c) The Author(s) 2015. This article is published with open access at Springerlink.com

\begin{abstract}
This study presents a rigorous computational framework for visualizing uncertainty of tsunami hazard and risk assessment. The methodology consists of three modules: (i) earthquake source characterization and stochastic simulation of slip distribution, (ii) tsunami propagation and inundation, and (iii) tsunami damage assessment and loss estimation. It takes into account numerous stochastic tsunami scenarios to evaluate the uncertainty propagation of earthquake source characteristics in probabilistic tsunami risk analysis. An extensive Monte Carlo tsunami inundation simulation is implemented for the 2011 Tohoku tsunami (focusing upon on Rikuzentakata along the Tohoku coast of Japan) using 726 stochastic slip models derived from eleven inverted source models. By integrating the tsunami hazard results with empirical tsunami fragility functions, probabilistic tsunami risk analysis and loss estimation are carried out; outputs from the analyses are displayed using various visualization methods. The developed framework is comprehensive, and can provide valuable insights in promoting proactive tsunami risk management and in improving emergency response capability.
\end{abstract}

Keywords Tsunami - Stochastic source modeling · Hazard/risk maps · Uncertainty · Visualization

Katsuichiro Goda

katsu.goda@bristol.ac.uk

1 Department of Civil Engineering, Queen's School of Engineering, University of Bristol, Queen's Building, University Walk, Bristol BS8 1TR, UK

\section{Introduction}

An extremely large subduction earthquake triggers massive tsunamis, which can destroy coastal cities and towns completely. Recent catastrophic tsunamis include the 2004 Indian Ocean tsunami (Borrero 2005; Murata et al. 2010) and the 2011 Great East Japan (Tohoku) tsunami (Fraser et al. 2013; Liu et al. 2013). To mitigate and control potential tsunami risk exposures effectively, physical protection and preparedness against anticipated tsunami events are of critical importance (FEMA 2008). One of the essential pieces of information for enhancing tsunami resilience of coastal communities is accurate tsunami hazard assessment; based on such hazard estimates, effective risk reduction countermeasures (e.g. breakwaters and seawalls) and evacuation strategies can be deployed. Current state-of-the-practice for preparing local/regional tsunami hazard maps is mainly concerned with tsunami hazard parameters that correspond to a single scenario on a single fault. It fails to assess uncertainty related to hazard predictions. Consequently, users of scenario-based tsunami hazard maps are unable to appreciate potential risks in different situations, inhibiting risk communications among tsunami experts, crisis managers, and local residents. For instance, during the 2011 Tohoku tsunami, more than $65 \%$ of all fatalities in Kamaishi, Iwate Prefecture, Japan, were caused outside the areas that were designated as major inundation zones in public tsunami hazard maps presented prior to 2005. The actual tsunami due to the 2011 Tohoku event was beyond historical events/scenarios that were taken into account in preparing the 2005 hazard map. Clearly, a set of tsunami inundation hazard maps, corresponding to different tsunami scenarios and consequences, is useful for tsunami hazard preparedness and evacuation planning in coastal cities and towns. Use of stochastic 
hazard maps that take into account the main sources of uncertainty related to the tsunami hazard assessment promotes the informed decisions regarding tsunami risk reduction actions by communicating the uncertainty of hazard predictions and by understanding the consequences in different situations.

Recent advances in tsunami hazard and risk mapping entail the quantification of uncertainty associated with tsunami modeling. Major sources of uncertainty in predicting tsunami wave heights and inundation extents can be attributed to source characteristics of future tsunamigenic earthquakes, such as location, magnitude, geometry, and slip distribution (Geist 2002; McCloskey et al. 2008; Løvholt et al. 2012; Fraser et al. 2014; Goda et al. 2014; Wiebe and Cox 2014; Fukutani et al. 2015; Mueller et al. 2015). New methods for developing stochastic earthquake source models, which are based on spectral analysis of slip heterogeneity of an inverted source model and spectral synthesis of slip random fields (Mai and Beroza 2002; Lavallée et al. 2006), facilitate the generation of possible scenarios having different earthquake slips and fault geometry. The approaches also allow the inclusion of epistemic uncertainty related to stochastic source modeling by considering multiple reference source models (Goda et al. 2014). By conducting Monte Carlo tsunami simulation based on numerous synthesized source models, stochastic inundation depth maps can be evaluated (Goda et al. 2015; Mueller et al. 2015). Furthermore, by integrating tsunami hazard estimates with tsunami fragility models (e.g. Koshimura et al. 2009; Reese et al. 2011; Suppasri et al. 2013; Tarbotton et al. 2015), stochastic tsunami risk maps (e.g. showing tsunami damage probability) as well as tsunami risk/loss curves (e.g. exceedance probability curve of tsunami loss for a building portfolio) at local/regional scales can be developed. Quantitative estimates of potential tsunami risk and loss are valuable for risk managers and emergency officers in making decisions for tsunami risk management. An advantage of such stochastic hazard/risk maps and curves is that the main sources of uncertainty related to the tsunami source characteristics are taken into account.

The physical processes of tsunami generation/propagation/inundation have crucial influence on how hazard analysis is formulated and conducted, and what mitigation measures can be adopted to protect our society and assets. Different stakeholders require different tsunami hazard/risk information related to potential effects on coastal communities and infrastructure over a variety of temporal and spatial scales. Understanding the meaning of hazard estimates with regard to epistemic uncertainty of hazard modeling processes is an essential part of probabilistic hazard analysis and thus visualization of the outcomes of an uncertainty assessment has become increasingly important. Novel source modeling combined with Monte Carlo tsunami simulation offers new ways of presenting and visualizing tsunami hazard analysis results, which are relevant for risk management actions. Various proposals for presentation and communication of hazard results have been discussed in the literature. The properties of key variables of interest have a significant impact on the selection of visualization methods. The variables may be multi-dimensional, and may be dependent spatially and temporally (e.g. tsunami wave profiles at two locations). The probabilistic characteristics of the variables can differ significantly (e.g. Gaussian variable versus non-Gaussian variable with heavy right tail). In these cases, simple metrics, such as mean and standard deviation (statistical moments), are not sufficient to convey underlying uncertainty of the hazard estimates, and some higher-order statistics as well as probability distribution may be presented graphically (Potter et al. 2010). For representing uncertainty of spatially varying quantities (e.g. tsunami inundation map), visual parameter cues, such as color, texture, transparency, clarity, and size, can be varied in a cartographic graphical system (MacEachren et al. 2005; Pang 2008; Kunz et al. 2011). Typically, these results are shown for average trends and possible ranges (e.g. mean plus/minus one/two standard deviations), and both forms of information can be displayed on the same map (e.g. using color contour and scattered dots/isolines; Kunz et al. 2011; Pappenberger et al. 2013). It is also important to recognize that the visualization of the analysis results itself (e.g. interpolation) creates uncertainty and potentially gives a false impression of accuracy of the hazard results (Pang 2008).

This study presents a rigorous approach for visualizing uncertain tsunami hazard/risk analysis outputs that are obtained from extensive Monte Carlo tsunami simulations by taking into account a wide range of earthquake source characteristics. It aims at demonstrating how rich information of Monte Carlo tsunami simulations can be summarized concisely and how it can be used for tsunami risk mitigation decisions effectively. The investigation is focused upon the 2011 Tohoku tsunami as a case study from retrospective viewpoints. The 2011 Tohoku event offers unique opportunities to carry out detailed tsunami hazard/risk assessments, because various data and models for earthquake source properties, inundation/run-up measurements, and tsunami damage records are available. The quality and amount of available information from the 2011 Tohoku earthquake are unprecedented in comparison with other previous events. For instance, reliable tsunami inundation and run-up survey results (more than 5000 locations) are available from the Tohoku Tsunami Joint Survey (TTJS) team (Mori et al. 2011), whereas tsunami damage data as well as building data for the Tohoku region 
(more than 250,000 buildings) are available from the Ministry of Land, Infrastructure, and Transportation (MLIT 2014). In representing the possible range of tsunami scenarios/source models in the Tohoku region that may be applicable to tsunami hazard mapping purposes, various inversion models are gathered from the literature (Ammon et al. 2011; Fujii et al. 2011; Hayes 2011; Iinuma et al. 2011, 2012; Shao et al. 2011; Yamazaki et al. 2011; Gusman et al. 2012; Satake et al. 2013), and numerous stochastic source models are then generated based on these reference source models (Goda et al. 2014). In the following, a computational framework of tsunami hazard and risk assessments for coastal cities and towns is presented based on Monte Carlo tsunami inundation simulations (Goda et al. 2015) and empirical tsunami fragility models (Suppasri et al. 2013). Various visualization methods of tsunami hazard/risk analysis are then illustrated through a case study focusing upon Rikuzentakata, a coastal city devastated by the 2011 Tohoku tsunami. A novel aspect of this study is that quantitative tsunami hazard and risk assessments are carried out by accounting for stochastic earthquake source properties and are presented with various visualization methods for improved tsunami risk mitigation actions and risk communications.

\section{Stochastic tsunami hazard and risk analysis}

A generic equation for probabilistic tsunami risk assessment can be expressed as:

$$
\begin{aligned}
v(L \geq l)= & \iiint_{\Omega_{D S, I M, E Q S}} P(L \geq l \mid d s) f_{D S \mid I M}(d s \mid i m) f_{I M \mid E Q S} \\
& \times(i m \mid e q s) f_{E Q S}(e q s)|\mathrm{d} d s||\mathrm{d} i m||\mathrm{d} \lambda(e q s)|
\end{aligned}
$$

where $v(L \geq l)$ is the annual exceedance probability that the tsunami loss $L$ of a structure exceeds a certain loss threshold $l, \lambda(e q s)$ is the annual occurrence rate of earthquake scenarios $(E Q S)$ represented by multiple physical parameters (e.g. magnitude, location, geometry, and slip distribution), $P(L \geq l l d s)$ is the tsunami loss function in terms of damage state variable $(D S), f_{D S \mid I M}$ is the tsunami fragility function in terms of intensity measure (IM), $f_{I M \mid E Q S}$ is the probability density function of $I M$ given $E Q S, f_{E Q S}$ is the probability density function of $E Q S$, and $\Omega_{D S, I M, E Q S}$ is the joint domain of integration for $D S, I M$, and $E Q S$. Note that $D S$ is often defined in a discrete manner; in such cases, integration for $D S$ in Eq. (1) can be replaced by summation. A typical $I M$ is the inundation depth, which is often used as an input parameter for tsunami fragility modeling (i.e. $\left.f_{D S I I M}\right) . f_{I M \mid E O S}$ is evaluated through numerical evaluations of governing equations for tsunami waves and inundation/run-up (e.g. solving the nonlinear shallow water equations for given initial boundary conditions). The uncertainty associated with variable earthquake source characteristics is captured by $f_{E Q S}$. When earthquake scenarios are defined for a single source region (i.e. scenariobased), the interpretation of Eq. (1) becomes conditional. Such conditional assessment may be considered for situations where dominant earthquake source regions are identified through historical tsunami records or probabilistic tsunami hazard analysis (e.g. Geist and Parsons 2006; Horspool et al. 2014), but their occurrence probabilities and potential earthquake sizes cannot be estimated reliably (Kagan and Jackson 2013). An advantage of the conditional evaluations is that the nonlinear physical processes of tsunami wave propagation and inundation as well as the uncertainty of detailed source characteristics can be fully incorporated in the hazard computation (Goda et al. 2014, 2015).

This section succinctly summarizes an analytical procedure for scenario-based tsunami hazard and risk assessments using stochastic source models that are derived from multiple reference models, focusing upon the 2011 Tohoku earthquake. The methodology consists of three major components, i.e. earthquake source characterization and stochastic simulation of slip distribution, tsunami propagation and inundation, and tsunami damage assessment of structures. A computational flow of the tsunami hazard and risk assessments is illustrated in Fig. 1.

\subsection{Stochastic source models}

An earthquake slip modeling procedure, which is based on spectral analysis of an inversion-based source model and spectral synthesis of random fields, generates earthquake slip distributions with statistical properties equivalent to the inverted source model. The method is based on Mai and Beroza (2002), and has been extended for large megathrust subduction earthquakes (Goda et al. 2014). A brief summary of the stochastic method is given below; full details of the method can be found in Goda et al. (2014) and are not repeated here.

The stochastic source models are dependent on the characteristics of the reference source model that is derived from inversion analysis. Because data and methods used for constraining the slip distribution over a fault plane differ significantly, details of the slip distribution and fault geometry differ significantly among the inversion models (e.g. moment magnitude, fault length and width, fault location, strike, dip, and asperities [i.e. large slip patches]; Panel A in Fig. 1). This reflects the complexity and uncertainty of the rupture process of mega-thrust subduction earthquakes. Therefore, to explore a range of possible slip distributions for a given scenario (i.e. epistemic 

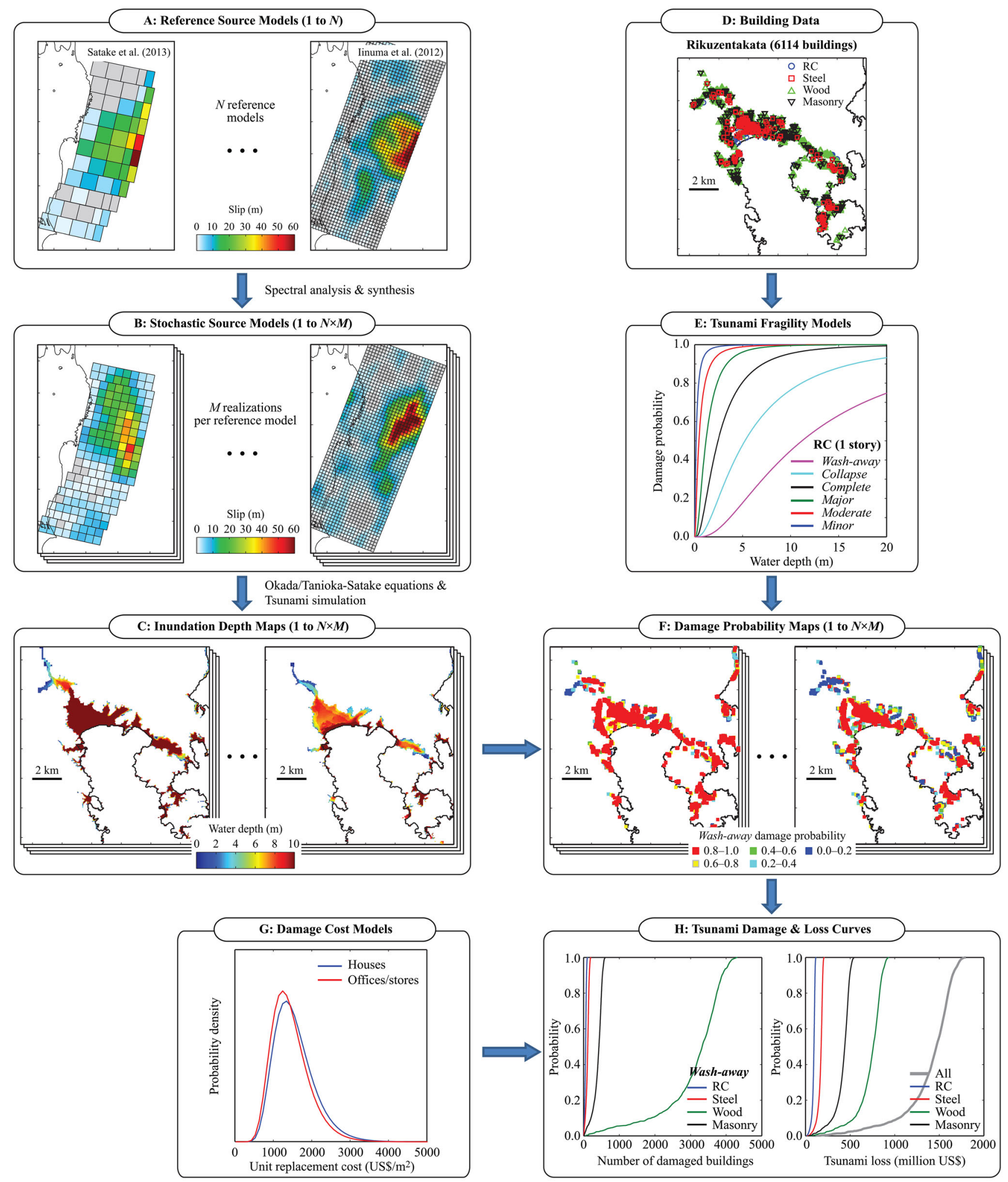

Fig. 1 Probabilistic tsunami loss estimation framework

uncertainty), multiple reference models should be considered for generating stochastic source models. In total, eleven source models that are developed using teleseismic/ tsunami/geodetic data are considered (Ammon et al. 2011; Fujii et al. 2011; Hayes 2011; Iinuma et al. 2011, 2012; Shao et al. 2011; Yamazaki et al. 2011; Gusman et al. 
2012; Satake et al. 2013), and are used as reference to further produce stochastic source models with variable characteristics.

The analytical procedure of generating stochastic source models from a given reference model is as follows. Firstly, key characteristics of the reference source model are obtained as slip statistics (mean and standard deviation) and asperity zone (i.e. a set of sub-faults that have slip values greater than a specified threshold value; typically, the threshold is set to two to three times the average slip). In addition, right tail characteristics of the slip distribution are modeled via Box-Cox transformation. The Box-Cox analysis is necessary because for the 2011 Tohoku earthquake, very large slip values (e.g. exceeding $40 \mathrm{~m}$ ) are obtained for a small number of sub-faults and thus distribution of earthquake slip significantly deviates from normal distribution with the same slip statistics (Goda et al. 2014). Secondly, after modifications to the original slip distribution (e.g. interpolation/resampling using finer grid sizes), fast Fourier transform (FFT) of the slip distribution is carried out to obtain the two-dimensional (2D) normalized power spectrum. The normalized power spectra in the down-dip and along-strike directions are then fitted by the power spectrum of a von Kármán auto-correlation function:

$P(k) \propto \frac{A_{x} A_{z}}{\left(1+k^{2}\right)^{H+1}}$,

where $k$ is the wavenumber, $k=\left(A_{\mathrm{z}}^{2} k_{\mathrm{z}}^{2}+A_{\mathrm{x}}^{2} k_{\mathrm{x}}^{2}\right)^{0.5}, A_{\mathrm{z}}$ and $A_{\mathrm{x}}$ are the correlation lengths for the down-dip and alongstrike directions, respectively, and $H$ is the Hurst number. $A_{\mathrm{x}}$ and $A_{\mathrm{z}}$ control the absolute level of the power spectrum in the low wavenumber range (i.e. $k<<1$ ) and capture the anisotropic spectral features of the slip distribution. $H$ determines the slope of the power spectral decay in the high wavenumber range, and is theoretically constrained to fall between 0 and 1 .

Thirdly, multiple realizations of slip distributions with desired stochastic properties are generated using a Fourier integral method. The amplitude spectrum of the target slip distribution is specified by the theoretical power spectrum with the estimated correlation lengths and Hurst number, while the phase spectrum is represented by a random phase matrix. The constructed complex Fourier coefficients are transformed into the spatial domain via 2D inverse FFT. The synthesized slip distribution is converted via Box-Cox transformation to achieve realistic heavy right-tail features of the slip distribution. To resemble the synthesized slip distribution with the original one in terms of location and amplitude of asperities, an asperity zone of the synthesized slip distribution is compared with that of the original slip distribution. An acceptable slip distribution is required to have its maximum slip patch and similar slip concentration within the asperity zone of the original distribution. Finally, the mean and standard deviation of the transformed slip distribution are adjusted to achieve similar statistics of the synthesized slip model with respect to the original slip model.

To generate source models that have different geometrical properties from the reference models, the top-edge depth, strike, and dip are varied over certain ranges with respect to the original models by changing one parameter at a time and by keeping a slip distribution identical to the original model. Geometrical parameters are allowed to vary as follows: the top-edge depth varies in steps of $2.5 \mathrm{~km}$ from by -2.5 to $+10 \mathrm{~km}$ with respect to the reference depth; the strike angle takes on values between $-5^{\circ}$ and $+7.5^{\circ}$ in $2.5^{\circ}$ increment with respect to the reference strike; the dip angle is changed between $-5^{\circ}$ and $+10.0^{\circ}$ in $2.5^{\circ}$ increment from the reference dip. The ranges of varied geometrical parameters are determined by examining various inverted source models for the 2011 Tohoku earthquake [see Goda et al. (2014) for more detailed information] and are consistent with the seismotectonic setting in the Tohoku region (i.e. physical characteristics of the subduction zone, such as the location of the Japan Trench and typical dip angles for the subducting slab). When parameters of an original source model are variable, an average value is used to define a reference case for each parameter. Moreover, for each of the eleven reference models, 50 realizations of a target slip distribution are generated using the stochastic synthesis method by keeping their geometrical parameters identical to those of the original models. In total, 726 slip distributions are generated for Monte Carlo tsunami simulation (66 cases per reference model, consisting of a reference case, 15 cases with varied geometrical parameters, and 50 cases with stochastic slip distributions; Panel B in Fig. 1).

\subsection{Monte Carlo tsunami simulation}

Tsunami modeling is carried out using a well-tested numerical code (Goto et al. 1997) that is capable of generating off-shore tsunami propagation and run-up/inundation by evaluating nonlinear shallow water equations using a leap-frog staggered-grid finite difference scheme. The run-up/inundation calculation is performed by a moving boundary approach, where a dry or wet condition of a computational cell is determined based on total water depth in comparison with its elevation. The computational domains are nested at four resolutions (i.e. 1350, 450, 150, and 50-m domains). Computational cells include those on land, and coastal defense structures are taken into account using overflowing formulae as a sub-grid model. In the tsunami simulation code that is used in this study, the coastal defense structures (e.g. breakwater and levee) are 
represented as vertical walls at one or two sides of the computational cells. To evaluate the volume of the water that overpasses these walls, Homma's overflowing formulae are employed. It is noteworthy that the destruction of the coastal defense structures during the tsunami simulation is not taken into account; this may result in underestimation of the tsunami inundation in coastal cities and towns.

Bathymetry/elevation data, roughness data, and information of coastal defense structures for the Tohoku region are obtained from the Cabinet Office of the Japanese Government. The ocean bathymetry data are based on the digital database and nautical charts developed by Japan Hydrographic Association and Japan Coastal Guard. The land elevation data are based on the $50-\mathrm{m}$ grid digital elevation model (DEM) developed by the Geospatial Information Authority of Japan. The bottom friction is evaluated using Manning's formula by considering four land use classes: $0.02 \mathrm{~m}^{-1 / 3} \mathrm{~s}$ for agricultural land, $0.025 \mathrm{~m}^{-1 / 3} \mathrm{~s}$ for ocean/water, $0.03 \mathrm{~m}^{-1 / 3} \mathrm{~s}$ for forest vegetation, and $0.04 \mathrm{~m}^{-1 / 3} \mathrm{~s}$ for urban areas. It is noted that the assigned roughness coefficients are crude representation of actual situations.

Differences in earthquake slip result in different boundary conditions for tsunami propagation and run-up. In tsunami simulation, the initial water surface elevation is evaluated based on formulae by Okada (1985) and Tanioka and Satake (1996). The latter equation accounts for the effects of horizontal seafloor movements in case of steep seafloor, inducing additional vertical water dislocation. Although the seafloor deformations are obtained for the same event, spatial characteristics of the seafloor displacements vary significantly among the models, leading to various tsunami wave profiles at different locations along the Tohoku coast (Goda et al. 2014). The fault rupture is assumed to occur instantaneously, and numerical tsunami calculation is performed for duration of $2 \mathrm{~h}$ with an integration time step of $0.5 \mathrm{~s}$. The tsunami simulation is conducted for the 726 source models. For each case, the maximum inundation depths at all in-land computational cells (50-m grids) are obtained by subtracting the DEM data from the calculated maximum wave heights (Panel $\mathrm{C}$ in Fig. 1).

\subsection{Tsunami fragility and damage analysis}

Structural vulnerability against tsunami loading can be modeled by empirical tsunami fragility curves, which relate tsunami intensity measures $(I M)$ to tsunami damage states $(D S)$ statistically. The damage states of structures are determined during reconnaissance survey and building inspection. The inundation depth is often adopted as $I M$, because the inundation depth is usually observable (e.g. water marks, post-tsunami interview, and numerical simulation). Mathematically, the tsunami fragility is modeled by the lognormal distribution. The exceedance probability of a damage state $d s_{\mathrm{i}}$ for a given value im is expressed as:

$P\left(D S \geq d s_{i} \mid i m\right)=\Phi\left(\left[\ln (i m)-\mu_{\ln I M \mid D S_{i}}\right] / \sigma_{\ln I M \mid D S_{i}}\right)$

where $\Phi$ is the cumulative distribution function of the standard normal variate, and $\mu_{\ln I M \mid D S \mathrm{i}}$ and $\sigma_{\ln I M \mid D S \mathrm{i}}$ are the mean and standard deviation of $\ln I M \mid D S_{\mathrm{i}}$, respectively. For mutually exclusive damage states that are defined in a discrete manner, the probability of being in $d s_{\mathrm{i}}$ is given by:

$p\left(d s_{i} \mid i m\right)=P\left(D S \geq d s_{i} \mid i m\right)-P\left(D S \geq d s_{i+1} \mid\right.$ im $)$

Note that $d s_{\mathrm{i}+1}$ is severer than $d s_{\mathrm{i}}$ (i.e. $P\left(D S \geq d s_{\mathrm{i}+1}\right.$ lim) $<P\left(D S \geq d s_{\mathrm{i}} \mid\right.$ im $\left.)\right)$.

In Japan, the MLIT (2014) implements a uniform classification scheme for tsunami damage survey. Seven discrete damage levels are defined: no damage, minor damage, moderate damage, major damage, complete damage, collapse, and wash-away. Furthermore, information regarding the structural material types and the number of stories is also provided. The material types are categorized into: reinforced concrete (RC), steel, wood, masonry, and unknown, whereas the number of stories is divided into: 1-story, 2-story, and $3+$-story (Panel D in Fig. 1). Using the extensive MLIT tsunami damage database for the 2011 Tohoku tsunami (more than 250,000 data points), Suppasri et al. (2013) developed tsunami fragility models by distinguishing tsunami damage data according to the structural materials and the number of stories (Panel E in Fig. 1). The refinement for the different material types as well as for the number of stories is desirable, because the tsunami capacities for RC, steel, wood, and masonry buildings differ significantly (Koshimura et al. 2009; Suppasri et al. 2013; Tarbotton et al. 2015).

Using the tsunami fragility curves, probabilities of attaining particular damage states $p(d s i m)$ can be estimated for each building and for each scenario (Panel F in Fig. 1). The statistical analysis can be then carried out to develop stochastic tsunami risk maps. For instance, representative percentiles of tsunami damage probability (e.g. 50th and 90th percentiles) can be displayed on a map to show the relative likelihood of tsunami damage occurrence at different spatial scales. Moreover, calculated values of tsunami damage probability can be used in Monte Carlo sampling to generate realizations of individual damage states for the buildings of interest. This resampling facilitates the development of the cumulative distribution functions of aggregate tsunami risk metrics, such as the number of buildings attaining a specific damage state (Panel H in Fig. 1). 
Finally, by incorporating damage cost models for different buildings (Panel G in Fig. 1), the tsunami damage information can be transformed into tsunami loss information for individual buildings as well as building portfolios (Panel $\mathrm{H}$ in Fig. 1). The loss ratios, which are typically used to represent damage as a percentage of total construction repair/replacement cost, can be assigned as: $0.0,0.05,0.2,0.4,0.6,1.0$, and 1.0 for the seven damage states (i.e. from no damage to wash-away) (MLIT 2014). Using the damage state probability $p(d s)$ and loss ratio $R_{\mathrm{L}}(d s)$, tsunami damage cost for a given tsunami hazard intensity can be calculated as (for discrete cases):

$L=C_{R} \sum_{i=1}^{7} p\left(d s_{i}\right) \times R_{L}\left(d s_{i}\right)$

where $C_{\mathrm{R}}$ is the replacement cost of a building. An advantage of using loss metrics, instead of damage probability or number of damaged buildings, is that the consequences due to tsunami damage in coastal cities/towns can be aggregated for the entire building portfolio; this facilitates the various financial risk management decisions (Yoshikawa and Goda 2014).

\section{Case study: 2011 Tohoku tsunami}

The main objective of this section is to demonstrate the uncertainty and visualization methods for tsunami hazard and risk assessments, which are introduced in the preceding section, through a real case study in the Tohoku region of Japan. Firstly, a brief summary of the analysis set-up is given. Subsequently, tsunami simulation results obtained from Monte Carlo analyses are visualized such that uncertain outcomes of the tsunami hazard and risk predictions are better displayed and used for further investigations.

\subsection{Problem set-up}

In this study, a set of 726 source models that are generated by considering the eleven reference models and by varying their source characteristics are adopted as a representative set. Figure $2 \mathrm{a}-\mathrm{c}$ show the earthquake source models by Satake et al. (2013), Ammon et al. (2011), and Iinuma et al. (2012) (for illustration), which have been derived from source inversion analyses using tsunami, teleseismic, and geodetic data, respectively. Inspection of the three reference models indicates that in addition to differences in fault plane geometry, the location and concentration of major asperities vary significantly. Figure $2 d-f$ present three sample realizations of stochastic slip models based on Satake et al. (2013) (i.e. Fig. 2a). Stochastically generated alternative models display the varied asperity characteristics, and thus a wide range of possible source models for the specified scenario can be analyzed to quantify their effects on tsunami wave heights, coastal inundation, and structural damage and loss to buildings.

For damage and loss assessments, a pre-2011 building portfolio in Rikuzentakata, Iwate Prefecture, Japan, is considered (Fig. 3). Rikuzentakata is situated on the northern shore of the Hirota Bay which is about $3.5 \mathrm{~km}$ wide. It was one of the most heavily impacted areas along the Tohoku ria coast (Fraser et al. 2013; Liu et al. 2013). The city spreads across the northern shore of the Hirota Bay for at least $1.65 \mathrm{~km}$ east to west and for around $1 \mathrm{~km}$ in the northern (inland) direction, while at its western side it is crossed by the Kesen River. Over the wide zone, the land elevation is very low and the tsunami inundation depth exceeded $12 \mathrm{~m}$ in the city center (with run-up reaching $19 \mathrm{~m}$ ); every timber frame house (predominantly twostory) was totally destroyed. The MLIT database contains 6,114 low-rise buildings (one- or two-story) in Rikuzentakata, which have material type information. The considered building portfolio consists of 143 RC structures, 265 steel structures, 4,963 wood structures, and 743 masonry structures (note: the adopted selection criterion essentially excludes relatively large buildings, such as schools, hospitals, and hotels). The tsunami fragility assessment is carried out using the tsunami fragility curves by Suppasri et al. (2013). Based on the tsunami damage classification scheme and damage-loss ratios suggested by the MLIT, tsunami damage costs for buildings in Rikuzentakata are evaluated. For simplicity (note: the MLIT database does not contain occupancy information for individual buildings), the buildings are classified into residential houses (wood) and commercial stores/offices ( $\mathrm{RC} /$ steel/masonry). The adopted replacement cost models for houses and stores/offices are the lognormal distribution. The mean and coefficient of variation $(\mathrm{CoV})$ of the unit replacement costs are obtained from the Japanese building cost information handbook published by Construction Research Institute (2011). Using the cost handbook, mean unit cost $=1,600 \mathrm{US} \$ / \mathrm{m}^{2}$ and $\mathrm{CoV}=0.320$ are adopted for wooden houses, whereas mean unit cost $=1,500$ US $\$$ / $\mathrm{m}^{2}$ and $\mathrm{CoV}=0.318$ are adopted for stores/offices (note: 1 US $\$=100$ yen). The adopted cost statistics are for the Tohoku region. Moreover, typical floor areas of wooden houses and stores/offices are determined based on the national construction statistics maintained by the MLIT (http://www.mlit.go.jp/toukeijouhou/chojou/stat-e.htm). In this study, floor areas of 130 and $540 \mathrm{~m}^{2}$ are adopted for wooden houses and stores/offices, respectively, by averaging the construction data for Miyagi and Iwate Prefectures during the period between 2012 and 2014 . 

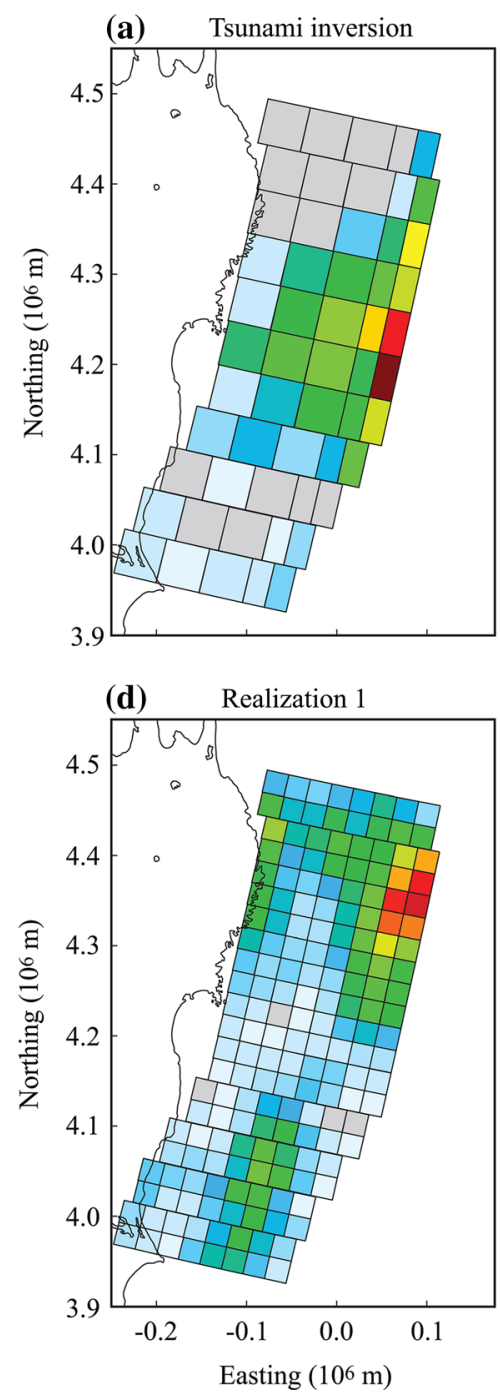

(b) Teleseismic inversion

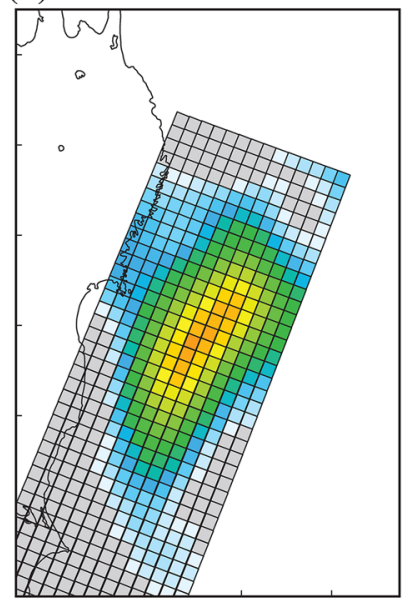

(e)

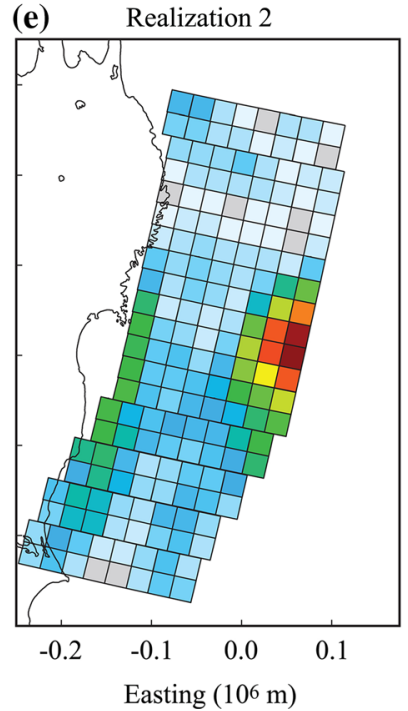

(c) Geodetic inversion

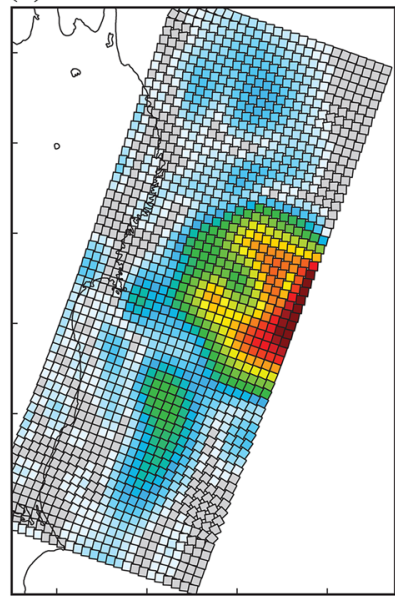

Slip (m)

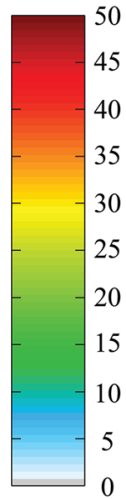

Fig. 2 Earthquake source models for the 2011 Tohoku earthquake: a Satake et al. (2013), b Ammon et al. (2011), c Iinuma et al. (2012), and d-f three synthesized models based on Satake et al. (2013)

\subsection{Visualizing uncertain tsunami hazard outcomes}

For the Tohoku event, tsunami waveforms recorded at nearshore GPS buoys (water depths between 150 and $200 \mathrm{~m}$ ) are available (Kawai et al. 2013) and can be used as benchmark in comparing simulated tsunami wave profiles with observed ones. Figure 4 shows a set of 726 simulated tsunami wave profiles at three GPS buoy stations (Fig. 3a), i.e. South Iwate (802G), North Miyagi (803G), and Central Miyagi (801G), in comparison with the observed ones. The simulated wave profiles are shown with grey lines, representing the entire variability of the Monte Carlo tsunami simulations. In addition to the individual results, three percentile curves (i.e. 10th/50th/90th percentiles) are included as summary statistics. It is interesting to observe that the median trend matches well with the observations in magnitude as well as in temporal profile, although the variability of the predicted tsunami waves is significant (which can be more than twice the observed profiles for some cases). Plots, such as Fig. 4, provide rich information regarding the overall performance (consistency) and variability of the tsunami simulations. Moreover, results shown in Fig. 4, when generated for locations at shallower water depths (e.g. 10-20 m), are useful for evaluating the reliability of coastal defense structures (e.g. breakwaters and seawalls) subjected to a wide range of tsunami waves. It is noteworthy that the variability of the tsunami simulations shown in Fig. 4 depends on the locations of the GPS buoy stations, indicating the sensitivity of the tsunami hazard estimates to the source characteristics as well as the topographical effects.

Figure 5a shows the variability of the maximum tsunami inundation height along the Tohoku coast; grey lines are the individual simulation results, whereas the black line is 
Fig. 3 Map of the Tohoku region and Rikuzentakata

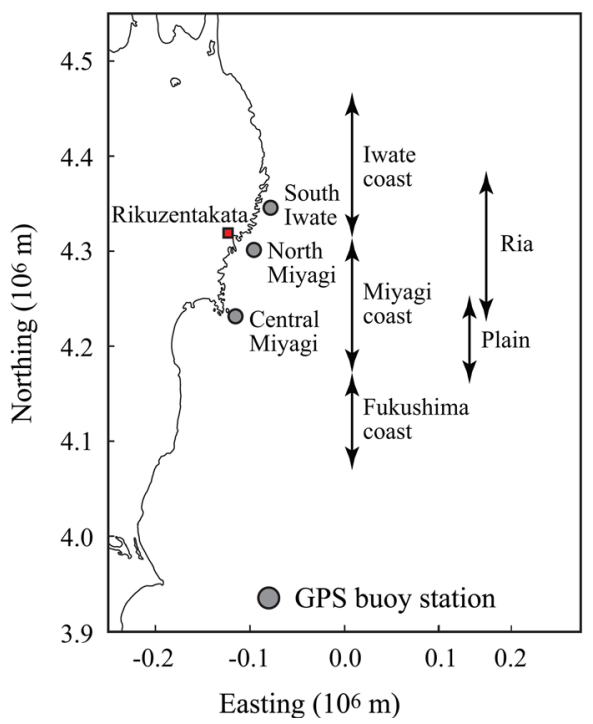

Buildings in Rikuzentakata

- RC : $143 \Delta$ Wood : 4,963

Steel: $265 \nabla$ Masonry: 743

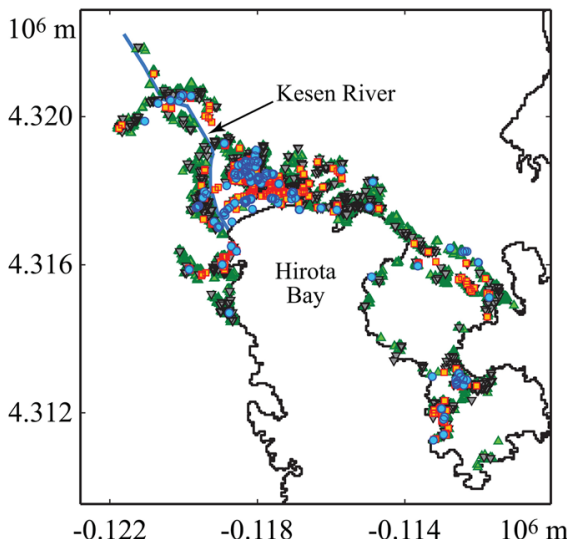

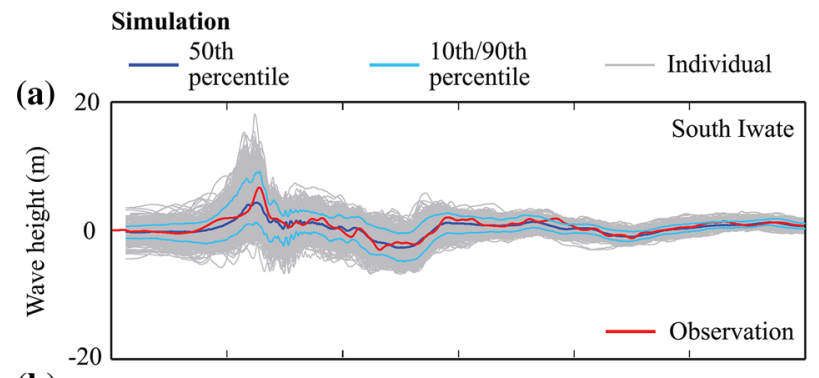
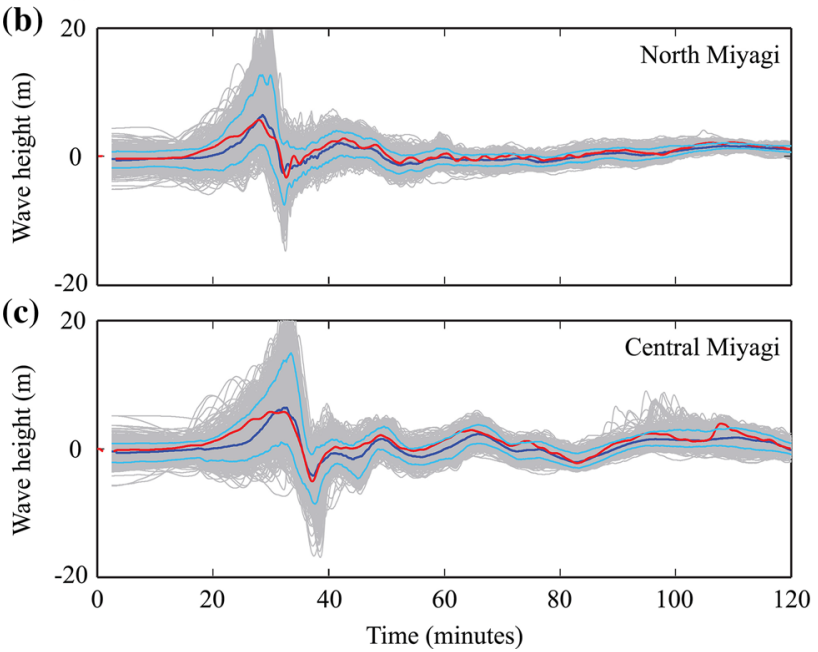

Fig. 4 Comparison of the simulated tsunami wave profiles with the observed wave profiles at GPS buoy stations: a South Iwate, b North Miyagi, and c Central Miyagi

the median of the 726 cases. For reference, the tsunami inundation heights from the TTJS database (Mori et al. 2011) are included in the figure. Compared with Fig. 4, Fig. 5a suppresses information related to the temporal variation of tsunami waveforms, but on the other hand presents rich information related to the spatial variability of

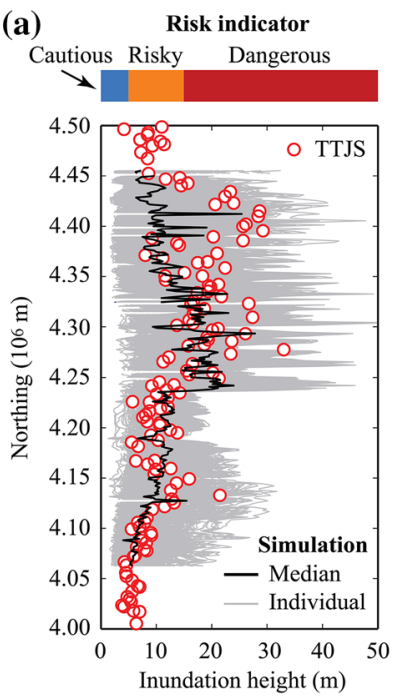

(b)

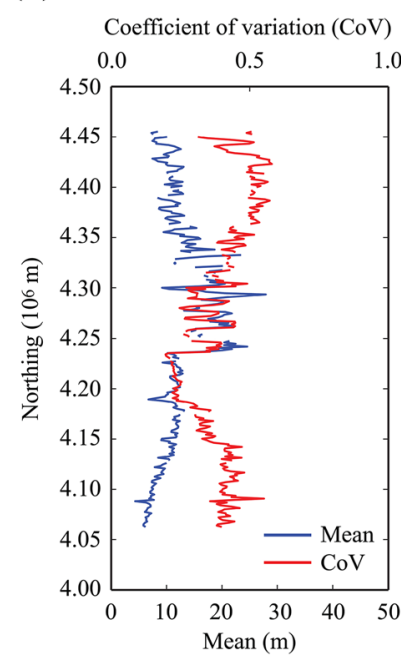

Fig. 5 a Variability of the maximum tsunami inundation heights along the coast in comparison with TTJS data, and $\mathbf{b}$ mean and $\mathrm{CoV}$ of the maximum tsunami inundation heights along the coast

the maximum inundation height. Individual results from the simulation exhibit significant variability of the inundation height due to stochastic tsunami scenarios. The median simulation results and the TTJS data are generally consistent in the southern and central parts of the Tohoku region (northing between $4.06 \times 10^{6}$ and $4.32 \times 10^{6}$ ), while a large discrepancy is noticed in the northern part of the Tohoku region (northing between $4.32 \times 10^{6}$ and $4.45 \times 10^{6}$ ). The latter is a known issue for inversion models of the 2011 Tohoku earthquake (Goda et al. 2014). In addition, a hypothetical risk indicator for tsunami inundation is included in Fig. 5a to illustrate how the tsunami hazard assessments can be used for tsunami risk 
management. Using the simulated tsunami results, for instance, the chance of attaining cautious/risky/dangerous risk levels can be evaluated for different locations.

The spatial variability of the maximum tsunami inundation height can be represented by the mean and $\mathrm{CoV}$ (Fig. 5b). Generally, the mean is larger in the ria part of the Tohoku coast (North Miyagi to Iwate), compared with other regions (e.g. coastal plains in southern Miyagi and Fukushima). On the other hand, the CoV decreases gradually from the northern Tohoku coast (e.g. Iwate) to the central Tohoku coast (e.g. Miyagi), and then increases towards the southern part of the Tohoku coast (e.g. Fukushima). This is because for the considered tsunami scenarios, large slip asperities are located off the Miyagi coast (i.e. common features of the inverted source models for the 2011 Tohoku tsunami); thus the extent of tsunami hazard variability is greater in the northern and southern Tohoku regions (and also affected by the topographical features). Since current design guidelines of tsunami evacuation buildings specify safety margins independent of coastal regions but buildings in a certain region are subjected to different levels of tsunami hazard variability, coastal infrastructure may not achieve consistent reliability levels across the Tohoku region against rare tsunami events.

Figure 6 shows the variability of the simulated tsunami wave profiles at three locations in Rikuzentakata (i.e. P1, $\mathrm{P} 2$, and P3 in the map). Because the three locations are at different elevations, the base levels of the simulated tsunami waves are different at these locations. In Fig. 6, individual results based on 726 scenarios as well as 10th, 50th, and 90th percentile curves are included. The results clearly show that the tsunami inundation height becomes smaller with increasing elevation and that the tsunami wave profiles are highly variable/uncertain, particularly at locations near shoreline (P1). The maximum tsunami inundation height can be greater than the median tsunami inundation height by a factor of 2 . It is noteworthy that the tsunami arrival time also varies significantly (10-15 min), implying that a time available for evacuation can differ greatly, depending on tsunami scenarios. The results presented in Fig. 6 are valuable input for analyzing tsunami vulnerability of a building, because tsunami inundation heights can be converted into tsunami forces acting on a building (FEMA 2008). Therefore, reliability of tsunamiproof buildings can be evaluated by considering different tsunami wave loadings.

Moreover, using the Monte Carlo tsunami simulation results for the 726 stochastic slip models, stochastic tsunami hazard maps for an area of interest (i.e. Rikuzentakata) can be developed [see Goda et al. (2014) for stochastic tsunami hazard maps at various locations along the Tohoku coast]. The level of tsunami hazard for a given scenario (i.e. $M_{\mathrm{w}}$ 9-class tsunamigenic event in the Tohoku region) can be specified by adopting a relevant tsunami hazard metric. In other words, stochastic tsunami inundation maps show spatial variation of the maximum inundation depth for different situations in terms of a chosen metric, and thus are useful for visualizing the uncertainty of tsunami hazard predictions in the form of cartographic map. An illustration is given in Fig. 7 . Figure 7 (middle) displays the probability distribution of inundation area above $1 \mathrm{~m}$ depth in Rikuzentakata based on all simulation results (i.e. 726 cases); in this case, the inundation area above $1 \mathrm{~m}$ depth is adopted to define the tsunami hazard level by ranking tsunami simulation results (note: different metrics can be adopted). Figure 7 (top) shows inundation depth maps for Rikuzentakata corresponding to three tsunami hazard levels: 50th percentile as a typical case and 10 th and 90th percentiles as rare cases. The set of inundation depth maps are useful for communicating with emergency officers and local residents regarding the uncertain tsunami hazard information. For the typical case (50th percentile), the majority of the city center of Rikuzentakata (northern side of the Hirota Bay; see Fig. 3b) is inundated by $8+\mathrm{m}$ tsunami waves. A similar feature is also observed for the extreme case (90th percentile). In contrast, significantly lower hazard level is indicated in the map for the 10th percentile level, where inundation depth of $8+m$ occurs near the shoreline only.

\subsection{Visualizing uncertain tsunami damage and loss outcomes}

Using applicable tsunami fragility models and damage cost models, inundation depth information from the Monte Carlo tsunami simulations can be transformed into tsunami risk and loss information for a building portfolio (Fig. 1). Figure 7 (bottom) shows the stochastic wash-away damage probability maps corresponding to the 10th, 50th, and 90th percentile levels in terms of inundation area above $1 \mathrm{~m}$ depth [i.e. Figure 7 (middle)]. Similar maps can be developed for different tsunami damage levels. In the maps, wash-away damage probabilities for individual buildings in Rikuzentakata (Fig. 3b) are color-coded and displayed. The stochastic damage probability maps are generated by integrating both local tsunami hazard level and physical vulnerability of structures. An advantage of the damage maps over the inundation depth maps [i.e. Fig. 7 (bottom) vs. Fig. 7 (top)] is noticed by comparing the two types of maps for the 10th percentile level. In these maps, a different pattern can be observed in the city center of Rikuzentakata near the shoreline; in the bottom-left map, several red markers are noticeable in the middle of the inundated areas, whereas in the top-left map, such local features are not present. These red markers in the damage 

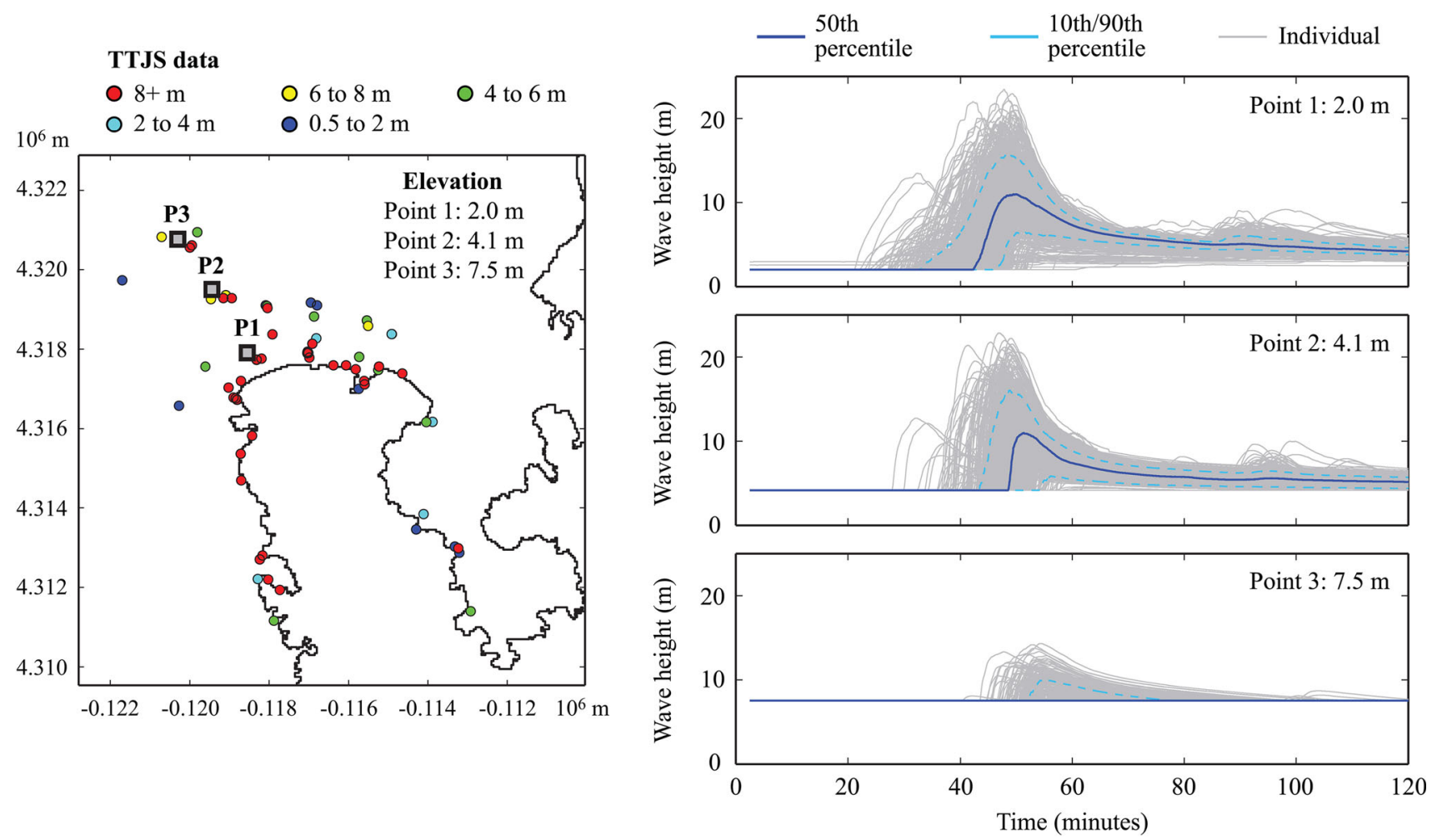

Fig. 6 Variability of the simulated tsunami wave profiles at three locations in Rikuzentakata

probability map correspond to a group of wooden houses in the city center which may be washed out by 4-8 $\mathrm{m}$ tsunami waves. Consideration of tsunami vulnerability of structures is useful for developing tsunami emergency response plans for local communities.

By implementing Monte Carlo sampling of the calculated damage probabilities for individual buildings, the cumulative distribution functions of the number of buildings in the wash-away damage state can be evaluated for the building portfolio in Rikuzentakata. For instance, when the estimated wash-away damage probability of a $\mathrm{RC}$ building is 0.2 (estimated using the corresponding tsunami fragility curve and inundation depth for a given tsunami scenario), a uniform random number between 0 and 1 can be generated; if the generated random number is less than 0.2 , the RC building is considered as washed out. The procedure can be applied to all buildings in Rikuzentakata, and can be used to develop the cumulative distribution functions of the number of damaged buildings. This transformation of the tsunami risk metric aggregates the tsunami impact to the coastal city/town into the number counts of damaged buildings. Such aggregated tsunami risk metrics are useful for risk management purposes. Figure $8 \mathrm{a}, \mathrm{b}$ show the cumulative distribution functions of the number of wash-away buildings in terms of structural type (RC/steel/wood/masonry) and reference source model (for stochastic slip generation), respectively. Figure 8 a shows that the number of wash-away buildings is dominated by wooden structures because of the large number of this construction type in Rikuzentakata (see Fig. 3) and their tsunami vulnerability compared with other types of structures. By taking into account the total number of buildings for each structural type, the tsunami damage curves shown in Fig. 8a can be presented in terms of damage ratio. It can be found that about $70 \%$ of wood structures are likely to be washed out at the 50th percentile level, this damage ratio is greater than those for other structural types, indicating greater tsunami vulnerability of wooden construction relative to other construction types (Suppasri et al. 2013).

Figure $8 \mathrm{~b}$ reorganizes the same tsunami risk analysis results in terms of reference inversion model for stochastic slip generation (note: the results do not distinguish different structural types). The results facilitate the appreciation of variability of tsunami damage curves due to different tsunami source characteristics. Although damage curves for different source models become more or less similar at high probability levels, wider variation of the damage curves is observed at low probability levels. This is because in worst-case situations, most of the source models place large slips directly off Rikuzentakata, while in the opposite situations, migration of large asperities towards north or south of Rikuzentakata depends on the characteristics of 
Stochastic inundation depth maps in terms of inundation area above $1 \mathrm{~m}$ depth

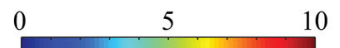

$(\mathrm{m})$
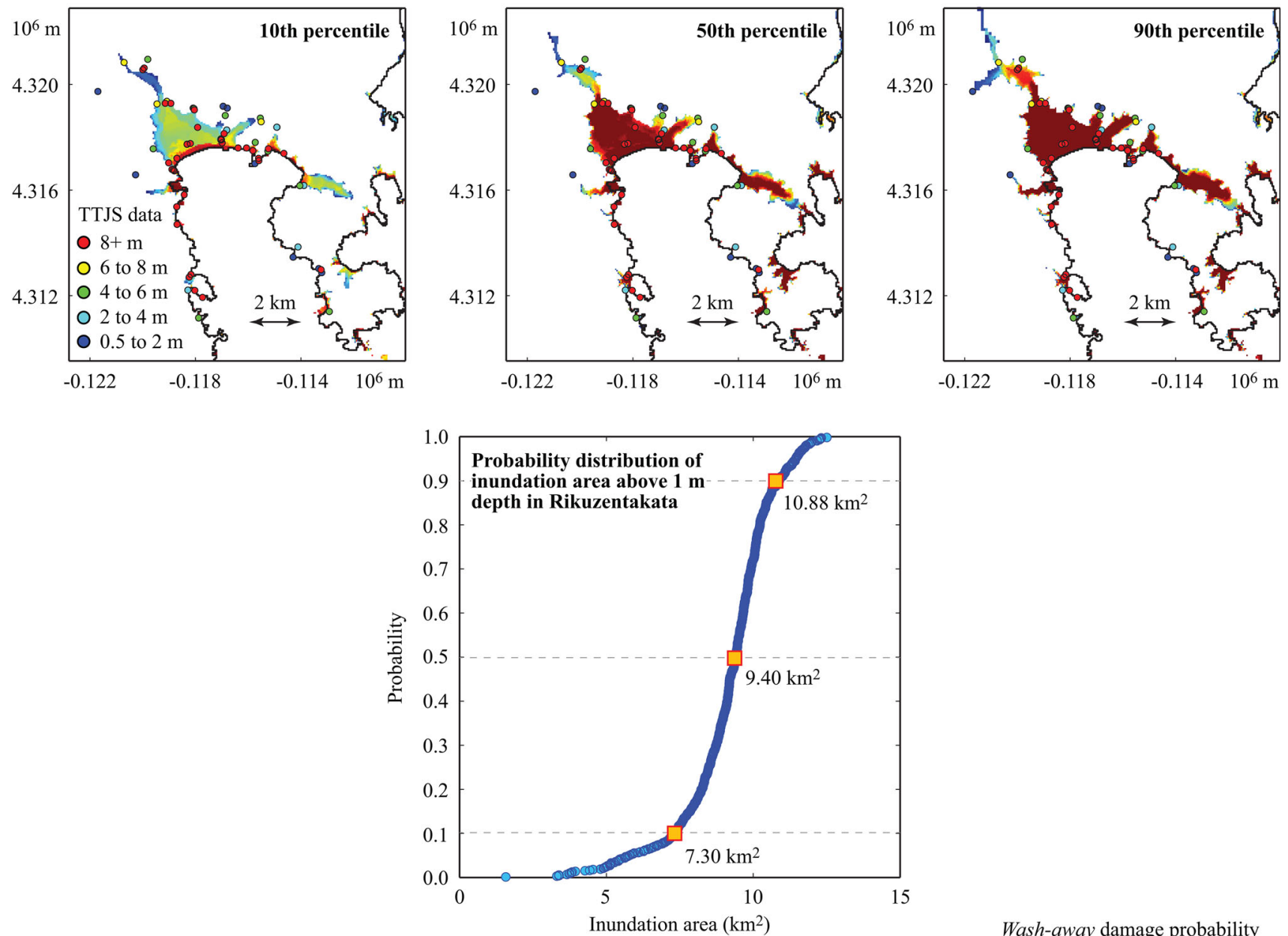

Stochastic wash-away damage probability maps in terms of inundation area above $1 \mathrm{~m}$ depth

Wash-away damage probability

$0.0-0.2 \square 0.2-0.4=0.4-0.6$

$\square 0.6-0.8 \square 0.8-1.0$
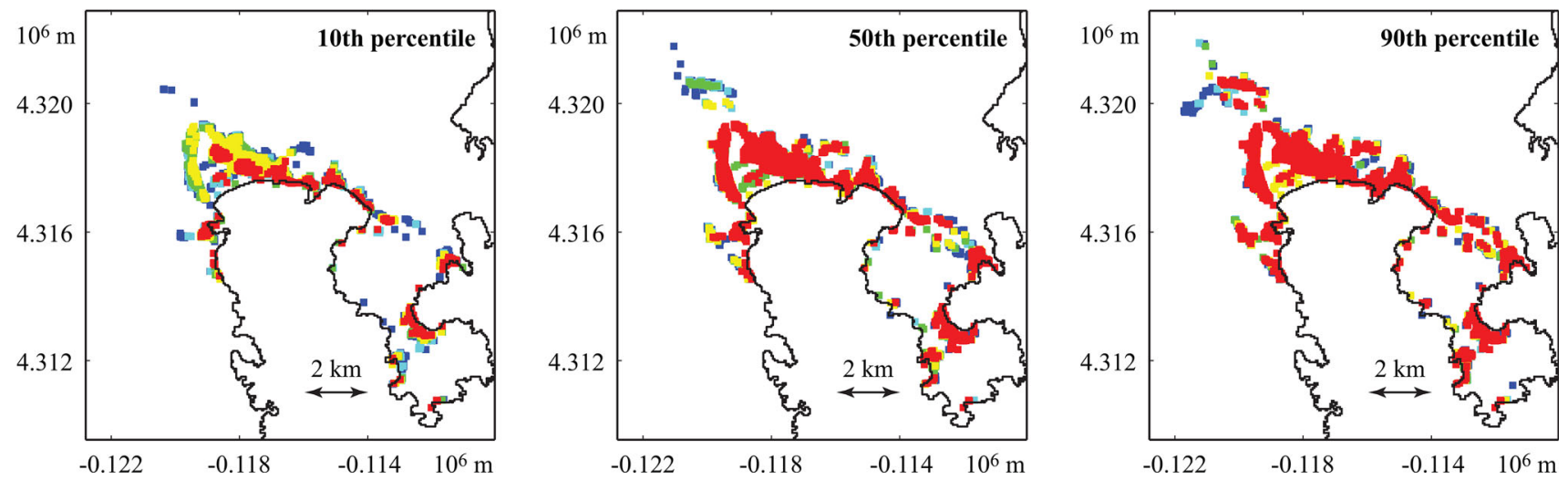

Fig. 7 Cumulative distribution function of inundation area above $1 \mathrm{~m}$ depth for Rikuzentakata (middle), stochastic inundation depth maps at 10th, 50th, and 90th percentile levels (top), and stochastic wash-away damage probability maps at 10th, 50th, and 90th percentile levels (bottom)

the reference source models. For instance, the difference between the minimum and maximum values of the number of wash-away buildings at the 50th percentile level is approximately 1000 with respect to the total number of 6114 buildings. Such results facilitate the quantification of epistemic uncertainty of the tsunami risk due to different source models.

The tsunami damage curves shown in Fig. 8 can be further transformed into the tsunami loss curves by using the damage cost models. Figure 9a, b show the cumulative 

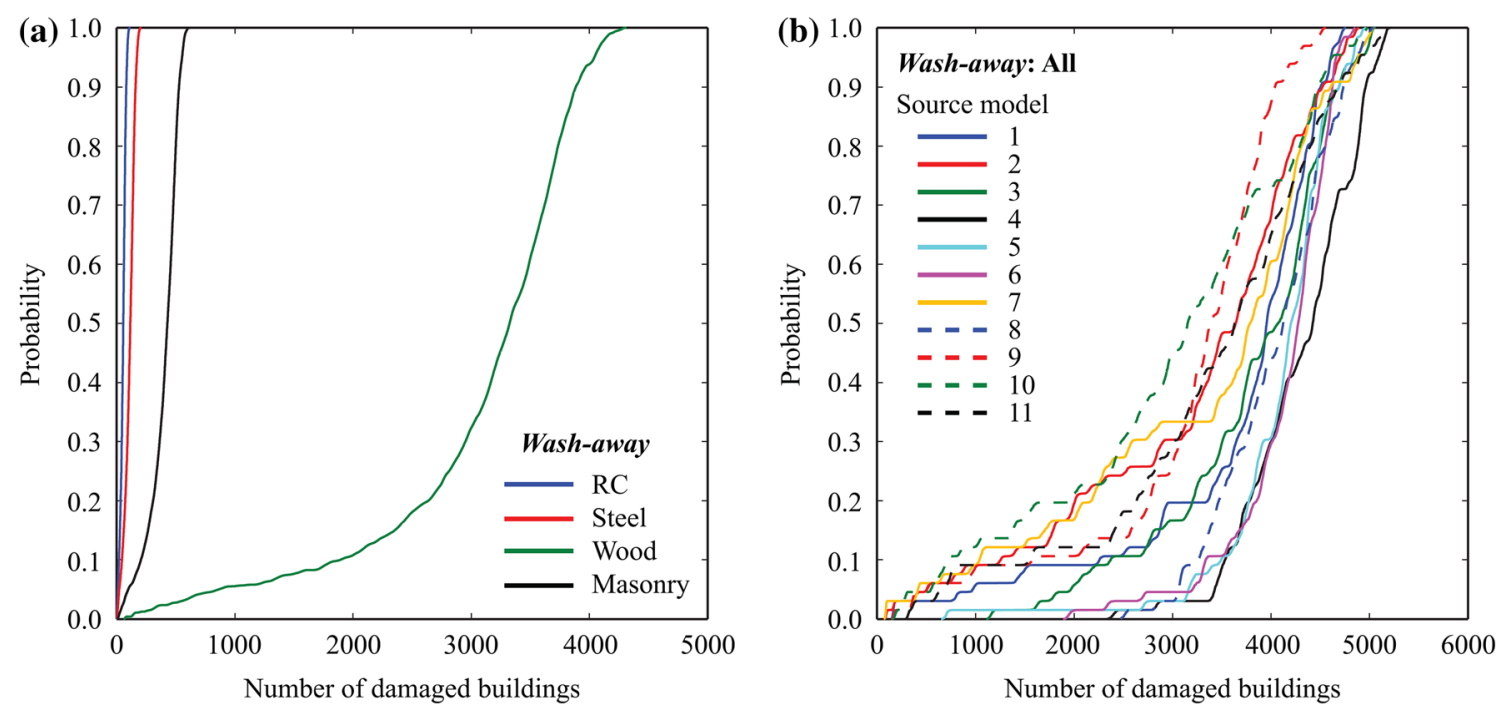

Fig. 8 Cumulative distribution functions of the number of buildings in the wash-away damage state for: a RC, steel, wood, and masonry structures by considering 726 source models, and $\mathbf{b}$ all structures by distinguishing eleven reference source models
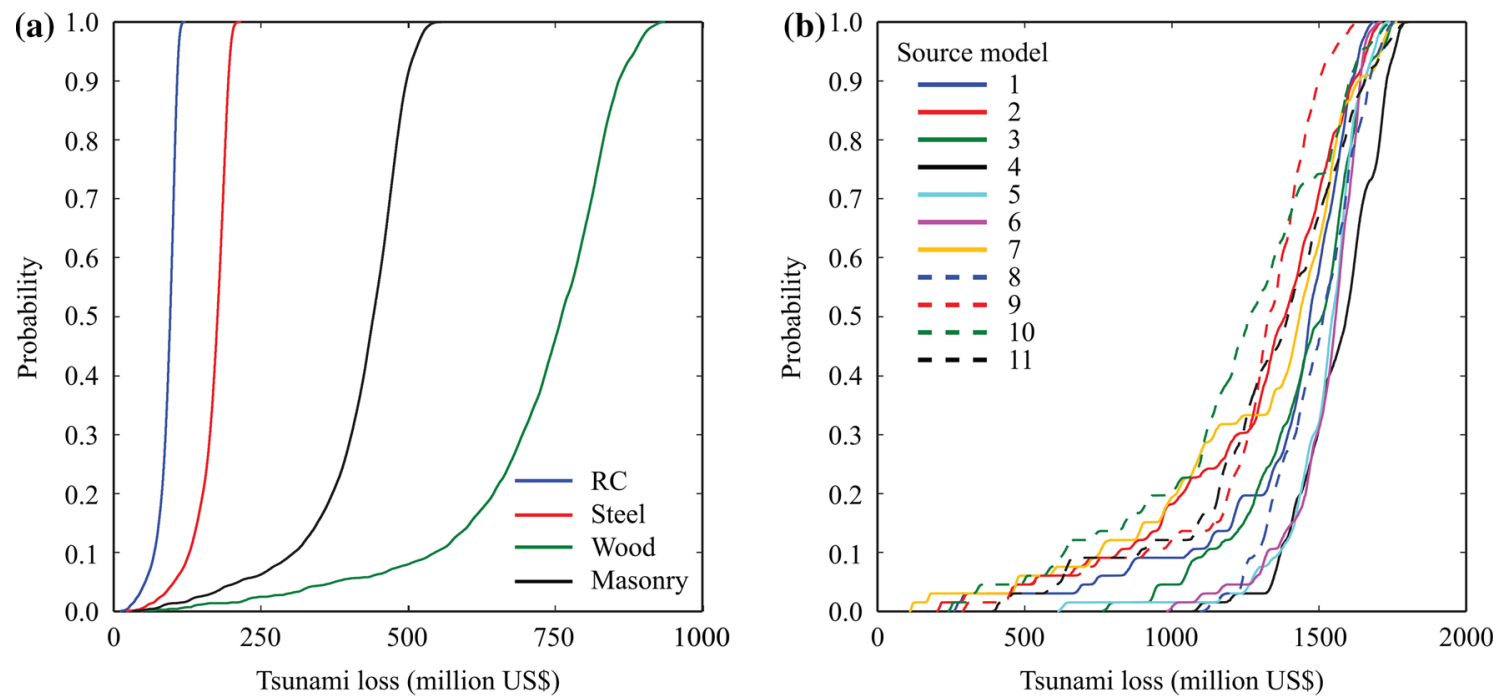

Fig. 9 Cumulative distribution functions of tsunami loss for: a RC, steel, wood, and masonry structures by considering 726 source models, and b all structures by distinguishing eleven reference source models

distribution functions of tsunami loss in terms of structural type and reference source model, respectively. An important difference between Figs. 8 and 9 is that in Fig. 9, tsunami loss for all buildings with different damage states is included in the tsunami loss curve by weighting their relative impact based on the tsunami damage cost. This is useful for assessing overall tsunami loss potential for the building portfolio (note: subdivision into different cases/categories is feasible). For instance, Fig. 9a shows that the predicted tsunami loss at the 50th percentile level for RC, steel, masonry and wood structures is approximately $80,170,440$, and 750 million US\$, respectively (in total, 1,440 million US\$). It is noteworthy that the tsunami loss curve for masonry structures becomes closer to that for wooden structures (Fig. 9a), in comparison with the counterparts shown in Fig. 8a. This is because in Fig. 9a, tsunami loss for all masonry buildings is taken into account, while in Fig. 8a, masonry buildings in the washaway damage state only is accounted for. In other words, because tsunami damage distribution for different types of structures can be quite different, aggregate risk metrics, such as monetary loss, may be suitable to represent the overall impact. Finally, Fig. 9b shows the similar tendency as Fig. $8 \mathrm{~b}$, indicating that the characteristics of the 
reference source models have major influence in terms of tsunami loss.

\section{Conclusions}

This paper proposed a computational framework of tsunami hazard and risk assessments for coastal areas by emphasizing the importance of uncertainty modeling and visualization. The improved method for tsunami source characterization generated hundreds of stochastic random-field slip distributions to quantify the uncertainty of tsunami hazard parameters. Subsequently, the uncertainty of tsunami hazard parameters was propagated through tsunami fragility models and damage cost models for an existing building portfolio to evaluate the tsunami damage probability and tsunami loss. Finally, the tsunami hazard and risk assessment results were displayed in various forms by focusing upon temporal and spatial variation of tsunami waves. In particular, stochastic tsunami inundation maps as well as tsunami damage probability maps were useful for succinctly presenting rich information from numerous tsunami simulations. When properly summarized and presented, these tools facilitate the risk communication with emergency officers and residents in a coastal community. In addition, tsunami damage curves in terms of the number of damaged buildings and tsunami loss curves in terms of monetary loss were promoted as effective tools for tsunami risk management. The developed methodology and tools were demonstrated through a case study for the 2011 Tohoku tsunami. Importantly, visualization of variable tsunami hazard and risk assessment results not only conveys a whole picture of tsunami impact to a coastal region but also facilitates deeper understanding of specific aspects of the tsunami hazard and risk assessments. This leads to more proactive and informed decisions for tsunami risk reduction.

Acknowledgments The bathymetry and elevation data for the Tohoku region were provided by the Cabinet Office of the Japanese Government. The run-up and inundation survey data were obtained from the 2011 Tohoku Earthquake Tsunami Joint Survey Group (http://www.coastal.jp/tsunami2011/). The tsunami damage data for the 2011 Tohoku earthquake were obtained from the Ministry of Land, Infrastructure, and Transportation (http://www.mlit.go.jp/toshi/ toshi-hukkou-arkaibu.html). The national statistics of the construction data in Japan are available from the Ministry of Land, Infrastructure, and Transportation (http://www.mlit.go.jp/toukeijouhou/chojou/state.htm). This work was supported by the Natural Environment Research Council through the Consortium on Risk in the Environment: Diagnostics, Integration, Benchmarking, Learning and Elicitation (CREDIBLE; NE/J017450/1).

Open Access This article is distributed under the terms of the Creative Commons Attribution 4.0 International License (http://crea tivecommons.org/licenses/by/4.0/), which permits unrestricted use, distribution, and reproduction in any medium, provided you give appropriate credit to the original author(s) and the source, provide a link to the Creative Commons license, and indicate if changes were made.

\section{References}

Ammon CJ, Lay T, Kanamori H, Cleveland M (2011) A rupture model of the 2011 off the Pacific coast of Tohoku earthquake. Earth Planets Space 63:693-696

Borrero J (2005) Field survey of northern Sumatra and Banda Aceh, Indonesia after the tsunami and earthquake of 26 December 2004. Seismol Res Lett 76:309-318

Construction Research Institute (2011) Japan building cost information 2011. Tokyo, Japan

Federal Emergency Management Agency (FEMA) (2008) Guidelines for design of structures for vertical evacuation from tsunamis. FEMA P646, Washington DC

Fraser S, Pomonis A, Raby A, Goda K, Chian SC, Macabuag J, Offord M, Saito K, Sammonds P (2013) Tsunami damage to coastal defences and buildings in the March 11th $2011 M_{\mathrm{w}} 9.0$ Great East Japan earthquake and tsunami. Bull Earthq Eng 11:205-239

Fraser S, Power WL, Wang X, Wallace LM, Mueller C, Johnston DM (2014) Tsunami inundation in Napier, New Zealand, due to local earthquake sources. Nat Hazards 70:415-445

Fujii Y, Satake K, Sakai S, Shinohara S, Kanazawa T (2011) Tsunami source of the 2011 off the Pacific coast of Tohoku earthquake. Earth Planets Space 63:815-820

Fukutani Y, Suppasri A, Imamura F (2015) Stochastic analysis and uncertainty assessment of tsunami wave height using a random source parameter model that targets a Tohoku-type earthquake fault. Stoch Environ Res Risk Assess. doi:10.1007/s00477-014-0966-4

Geist EL (2002) Complex earthquake rupture and local tsunamis. J Geophys Res Solid Earth. doi:10.1029/2000JB000139

Geist EL, Parsons T (2006) Probabilistic analysis of tsunami hazards. Nat Hazards 37:277-314

Goda K, Mai PM, Yasuda T, Mori N (2014) Sensitivity of tsunami wave profiles and inundation simulations to earthquake slip and fault geometry for the 2011 Tohoku earthquake. Earth Planets Space 66:1-20. doi:10.1186/1880-5981-66-105

Goda K, Yasuda T, Mori N, Mai PM (2015) Variability of tsunami inundation footprints considering stochastic scenarios based on a single rupture model: application to the 2011 Tohoku earthquake. J Geophys Res Oceans 120:4552-4575

Goto C, Ogawa Y, Shuto N, Imamura F (1997) Numerical method of tsunami simulation with the leap-frog scheme. IOC Manual, UNESCO, No. 35, Paris, France

Gusman AR, Tanioka Y, Sakai S, Tsushima H (2012) Source model of the great 2011 Tohoku earthquake estimated from tsunami waveforms and crustal deformation data. Earth Planet Sci Lett 341-344:234-242

Hayes GP (2011) Rapid source characterization of the $2011 M_{\mathrm{w}} 9.0$ off the Pacific coast of Tohoku earthquake. Earth Planets Space 63:529-634

Horspool N, Pranantyo I, Griffin J, Latief H, Natawidjaja DH, Kongko W, Cipta A, Bustaman B, Anugrah SD, Thio HK (2014) A probabilistic tsunami hazard assessment for Indonesia. Nat Hazards Earth Syst Sci 14:3105-3122

Iinuma T, Ohzono M, Ohta Y, Miura S (2011) Coseismic slip distribution of the 2011 off the Pacific coast of Tohoku earthquake (M9.0) estimated based on GPS data— was the asperity in Miyagioki ruptured? Earth Planets Space 63:643-648

Iinuma T, Hino R, Kido M, Inazu D, Osada Y, Ito Y, Ohzono M, Tsushima H, Suzuki S, Fujimoto H, Miura S (2012) Coseismic slip distribution of the 2011 off the Pacific coast of Tohoku 
earthquake (M9.0) refined by means of seafloor geodetic data. J Geophys Res Solid Earth. doi:10.1029/2012JB009186

Kagan Y, Jackson DD (2013) Tohoku earthquake: a surprise? Bull Seismol Soc Am 103:1181-1194

Kawai H, Satoh M, Kawaguchi K, Seki K (2013) Characteristics of the 2011 Tohoku tsunami waveform acquired around Japan by NOWPHAS equipment. Coast Eng J 55:1350008. doi:10.1142/ S0578563413500083

Koshimura S, Oie T, Yanagisawa H, Imamura F (2009) Developing fragility functions for tsunami damage estimation using numerical model and post-tsunami data from Banda Aceh, Indonesia. Coast Eng J 51:243-273

Kunz M, Gret-Regamey A, Hurni L (2011) Visualization of uncertainty in natural hazards assessments using an interactive cartographic information system. Nat Hazards 59:1735-1751

Lavallée D, Liu P, Archuleta RJ (2006) Stochastic model of heterogeneity in earthquake slip spatial distributions. Geophys J Int 165:622-640

Liu H, Shimozono T, Takagawa T, Okayasu A, Fritz HM, Sato S, Tajima Y (2013) The 11 March 2011 Tohoku tsunami survey in Rikuzentakata and comparison with historical events. Pure Appl Geophys 170:1033-1046

Løvholt F, Pedersen G, Bazin S, Kuhn D, Bredesen RE, Harbitz C (2012) Stochastic analysis of tsunami runup due to heterogeneous coseismic slip and dispersion. J Geophys Res Oceans. doi:10.1029/2011JC007616

MacEachren AM, Robinson A, Hopper S, Gardner S, Murray R, Gahegan M, Hetzler E (2005) Visualizing geospatial information uncertainty: what we know and what we need to know. Cartogr Geogr Inf Sci 32:139-160

Mai PM, Beroza GC (2002) A spatial random field model to characterize complexity in earthquake slip. J Geophys Res Solid Earth. doi:10.1029/2001JB000588

McCloskey J, Antonioli A, Piatanesi A, Sieh K, Steacy S, Nalbant S, Cocco M, Giunchi C, Huang JD, Dunlop P (2008) Tsunami threat in the Indian Ocean from a future megathrust earthquake west of Sumatra. Earth Planet Sci Lett 265:61-81

Ministry of land infrastructure and transportation (MLIT) (2014) Survey of tsunami damage condition. http://www.mlit.go.jp/ toshi/toshi-hukkou-arkaibu.html. Accessed 1 July 2014

Mori N, Takahashi T, Yasuda T, Yanagisawa H (2011) Survey of 2011 Tohoku earthquake tsunami inundation and run-up. Geophys Res Lett. doi:10.1029/2011GL049210

Mueller C, Power WL, Fraser S, Wang X (2015) Effects of rupture complexity on local tsunami inundation: implications for probabilistic tsunami hazard assessment by example. J Geophys Res Solid Earth 120:488-502. doi:10.1002/2014JB011301
Murata S, Imamura F, Katoh K, Kawata Y, Takahashi S, Takayama T (2010) Tsunami: to survive from tsunami. World Scientific Publishing, New Jersey

Okada Y (1985) Surface deformation due to shear and tensile faults in a half-space. Bull Seismol Soc Am 75:1135-1154

Pang A (2008) Visualizing uncertainty in natural hazards. Risk Gov Soc 14:261-294

Pappenberger F, Stephens E, Thielen J, Slamon P, Demeritt D, van Andel SJ, Wetterhall F, Alfieri L (2013) Visualizing probabilistic flood forecast information: expert preferences and perceptions of best practice in uncertainty communication. Hydrol Process 27:132-146

Potter K, Kniss J, Riesenfeld R, Johnson CR (2010) Visualizing summary statistics and uncertainty. Comput Graph Forum $29: 823-832$

Reese S, Bradley BA, Bind J, Smart G, Power WL, Sturman J (2011) Empirical building fragilities from observed damage in the 2009 South Pacific tsunami. Earth Sci Rev 107:156-173

Satake K, Fujii Y, Harada T, Namegaya Y (2013) Time and space distribution of coseismic slip of the 2011 Tohoku earthquake as inferred from tsunami waveform data. Bull Seismol Soc Am 103:1473-1492

Shao G, Li X, Ji C, Maeda T (2011) Focal mechanism and slip history of the $2011 M_{\mathrm{w}} 9.1$ off the Pacific coast of Tohoku earthquake, constrained with teleseismic body and surface waves. Earth Planets Space 63:559-564

Suppasri A, Mas E, Charvet I, Gunasekera R, Imai K, Fukutani Y, Abe Y, Imamura F (2013) Building damage characteristics based on surveyed data and fragility curves of the 2011 Great East Japan tsunami. Nat Hazards 66:319-341

Tanioka Y, Satake K (1996) Tsunami generation by horizontal displacement of ocean bottom. Geophys Res Lett 23:861-864

Tarbotton C, Dall'Osso F, Dominey-Howes D, Goff J (2015) The use of empirical vulnerability functions to assess the response of buildings to tsunami impact: comparative review and summary of best practice. Earth Sci Rev 142:120-134

Wiebe DM, Cox DT (2014) Application of fragility curves to estimate building damage and economic loss at a community scale: a case study of Seaside, Oregon. Nat Hazards 71:2043-2061

Yamazaki Y, Lay T, Cheung KF, Yue H, Kanamori H (2011) Modeling near-field tsunami observations to improve finite-fault slip models for the 11 March 2011 Tohoku earthquake. Geophys Res Lett. doi:10.1029/2011GL049130

Yoshikawa H, Goda K (2014) Financial seismic risk analysis of building portfolios. Nat Hazards Rev 15:112-120 